\title{
Intraoperative injuries from abdominopelvic surgery: an analysis of national medicolegal data
}

\author{
Guylaine Lefebvre, MD \\ Kirsten A. Devenny, BScN, \\ $\mathrm{MSc}(\mathrm{HQ})$ \\ Diane L. Héroux, BScN \\ Cara L. Bowman, MHSc \\ Heather K. Neilson, MSc \\ Richard Mimeault, MD \\ Sukhbir S. Singh, MD \\ Lisa A. Calder, MD, MSc
}

Presented at the Canadian Surgery Forum 2018, Sept. 13-15, 2018, St. John's, Nfld.

Accepted Mar. 17, 2020

\section{Correspondence to: \\ L. Calder}

Canadian Medical Protective Association 875 Carling Ave

Ottawa ON K1S 5P1

research@cmpa.org

DOI: $10.1503 /$ cjs.010219
Background: Intraoperative injuries during abdominopelvic surgery can be associated with substantial patient harm. The objective of this study was to describe abdominopelvic intraoperative injuries and their contributing factors among medicolegal cases.

Methods: This study was a descriptive analysis of medicolegal matters reported to a national body, with subgroup analyses by type of surgery. We reviewed medicolegal matters involving a population-based sample of physicians who were subject to a civil legal action or complaint to a regulatory authority that was closed between 2013 and 2017 in Canada.

Results: Our analysis included 181 civil legal cases and 88 complaints to a regulatory authority. Among legal cases, 155 patients (85.6\%) (median age $47 \mathrm{yr}$ ) underwent elective procedures. The most common injury site was the bowel (53 cases [29.3\%]). Injuries frequently occurred during dissection (79 [43.6\%]) and ligation (38 [21.0\%]), were identified postoperatively $(138[76.2 \%])$ and necessitated further surgery $(139[76.8 \%])$. Many patients experienced severe harm (55 [30.4\%]) or died (25 [13.8\%]). Peer experts in nongynecologic cases were more likely than those in gynecologic cases to include criticisms of a provider in a harmful incident (79 [71.2\%] v. 30 [42.9\%], $p<0.01)$. Peer expert criticisms often related to clinical evaluation, decision-making and misidentification of anatomy. Criticisms of nontechnical skills identified documentation and communication deficiencies.

Conclusion: This study confirms the importance of provider and team training to improve clinical evaluation and decision-making, documentation and communication. Effective protocols may help support clinicians in providing safer surgical care.

Contexte : Les blessures survenant durant une chirurgie abdominopelvienne peuvent être associées à d'importants préjudices chez les patients. La présente étude avait pour but de décrire les blessures peropératoires abdominopelviennes faisant l'objet d'enquêtes médicolégales et à connaître leurs facteurs contributifs.

Méthodes : Cette étude comprend une analyse descriptive d'affaires médicolégales signalées à un organisme de réglementation national, ainsi que des analyses par sousgroupes selon le type de chirurgie. Nous avons examiné des cas impliquant un échantillon de médecins canadiens représentatifs de la population qui avaient fait l'objet d'une poursuite au civil ou d'une plainte auprès d'un organisme de réglementation. Toutes les poursuites et plaintes étudiées ont été résolues entre 2013 et 2017.

Résultats : Notre analyse comprenait 181 poursuites au civil et 88 plaintes auprès d'un organisme de réglementation. En ce qui concerne les poursuites au civil, 155 patients $(85,6 \%)$ (âge médian 47 ans) avaient subi une intervention non urgente. Les blessures déclarées touchaient généralement les intestins (53 cas [29,3\%]). Elles sont fréquemment survenues durant la dissection (79 cas $[43,6 \%])$ et la ligature (38 cas [21,0\%]), ont été repérées en période postopératoire (138 cas [76,2\%]) et ont nécessité une autre chirurgie (139 cas [76,8\%]). De nombreux patients ont subi de graves préjudices (55 cas [30,4\%]) ou sont décédés (25 cas [13,8\%]). Les pairs experts dans un domaine autre que la gynécologie étaient plus susceptibles que ceux experts en gynécologie de critiquer un fournisseur en cas d'incident avec préjudice (79 cas [71,2\%] c. 30 cas $[42,9 \%] ; p<0,01)$. Les critiques formulées par les pairs experts portaient souvent sur l'évaluation clinique, la prise de décision et les erreurs d'identification des structures anatomiques. Les critiques visant les habiletés non techniques avaient trait aux lacunes dans la documentation et la communication.

Conclusion : Cette étude vient confirmer l'importance que revêt la formation des fournisseurs et de leur équipe dans l'amélioration de la prise de décision, de la documentation et de la communication. Des protocoles efficaces pourraient soutenir l'offre de soins chirurgicaux sûrs par les professionnels de la santé. 
I n the 1990s, researchers estimated that patient safety incidents occurred in $2.9 \%-3.7 \%$ of hospital admissions, with up to one-third deemed preventable and almost half attributed to surgical care. ${ }^{1-3}$ Subsequent studies suggested these rates were underestimated. ${ }^{4,5}$ By 2016, in Canada, preventable harm related to health care affected an estimated $5.6 \%$ of all patients admitted to hospital ${ }^{6}$ despite the introduction of major surgical safety initiatives such as national quality-improvement programs ${ }^{7}$ and the World Health Organization's surgical safety checklist. ${ }^{7,8}$

Patients undergoing surgery have the highest rate of safety incidents of all patients admitted to hospital. ${ }^{1,6}$ Intraoperative injuries affecting the ureters, ${ }^{9,10}$ bowel $^{11,12}$ and surrounding vasculature ${ }^{13}$ have all been reported in the literature. The level of harm seen with surgical injuries can be devastating for everyone involved. ${ }^{14}$ Intraoperative injuries are also a source of litigation against surgeons and hospitals. Between 2013 and 2017, the Canadian Medical Protective Association (CMPA), a national medicolegal defence organization for physicians, paid more than $\$ 29$ million in settlements and awards to patients in cases involving injury during abdominopelvic surgery.

Previous research aimed to describe the prevalence of intraoperative injuries and their associated risk factors, management, patient outcomes and, sometimes, medicolegal risk. ${ }^{10,13,15,16}$ These studies, however, often focused on only 1 surgical specialty area, ${ }^{10,15}$ surgical approach ${ }^{16}$ or type of injury. ${ }^{13}$ Medicolegal data offer valuable contextual information about medical errors - including the clinical management, contributing factors and long-term outcomes which may help to focus quality-improvement activities. ${ }^{17}$

We analyzed data from a national medicolegal repository with a focus on intraoperative injuries during abdominopelvic surgery. Our specific aims were to describe the frequency and types of injuries that occurred, clinical management of the injuries, contributing factors (based on peer expert and regulatory authority opinion in the medicolegal matters), patient outcomes and medicolegal outcomes. We also explored differences between gynecologic and nongynecologic surgery cases. We hypothesized that general surgeons may have a lower risk of involvement in a medicolegal matter involving bowel injury since they would likely repair the bowel without involving other specialists.

\section{Methods}

\section{Study design}

We conducted a retrospective descriptive analysis of CMPA files comprising civil legal actions or complaints to a regulatory authority. Civil legal actions (legal cases) were the focus of our primary analysis. Regulatory authority complaints were the focus of an in-depth secondary analysis of nontechnical contributing factors only. This approach was based on our prior knowledge that regula- tory authorities tend to appraise surgeons' nontechnical skills in more detail than do peer experts in legal cases. The study protocol was reviewed and approved by the Advarra Institutional Review Board.

\section{Data repository and medicolegal coding}

At the time of this study, the CMPA represented more than 97000 physician members (> 95\% of Canadian physicians) and maintained a national repository of coded medicolegal data relating to civil legal actions and complaints to physician regulatory authorities (i.e., provincial colleges of physicians and surgeons, territorial medical regulatory authorities). The CMPA records were organized by "case," representing instances in which a physician contacted the CMPA regarding a medicolegal matter.

Medical analysts at the CMPA reviewed each case and coded specific clinical details using the enhanced Canadian version of the International Statistical Classification of Diseases and Related Health Problems, 10th revision ${ }^{18}$ and the Canadian Classification of Health Interventions. ${ }^{19}$ Analysts used an in-house coding framework ${ }^{20}$ to categorize patient safety incidents and contributing factors (categorized as provider-, team- or system-related) based on peer expert opinion (see Appendix 1, Supplemental Table S1, available at canjsurg.ca/010219-a1, for a glossary of medicolegal terms).

Analysts used a classification system based on the American Society for Healthcare Risk Management's Healthcare Associated Preventable Harm Classification, ${ }^{21}$ which allows for categorizing harm due to inherent risks of health care, a near miss or no harm (Appendix 1, Supplemental Table S1). The system further classifies the level of patient harm (death, severe, moderate, mild or asymptomatic).

\section{Case selection}

All of the included cases involved surgeons who performed abdominopelvic surgery (see Appendix 1, Supplemental Figure S1 for selection criteria and Supplemental Tables S2 and S3 for inclusion codes). These surgeons were CMPA members who were named in a civil legal action or complaint to a regulatory authority. For inclusion, cases must have involved a patient injury during the intraoperative phase of care or a retained surgical item. The case must have closed with the CMPA (i.e., a final medicolegal outcome was determined by the court or regulatory authority, or there was mutual agreement between the parties to resolve the action) between Jan. 1, 2013, and Dec. 31, 2017.

We excluded cases involving the management of postoperative complications not related to an intraoperative injury (e.g., pneumonia) and cases with a date of occurrence older than 20 years (i.e., before 1998). We also excluded obstetrics-related cases and class action suits. 


\section{Data collected}

We examined the following variables: patient characteristics, type of intraoperative injury and mechanism of injury, timing of injury recognition, management of injury and patient outcome, medicolegal outcomes and contributing factors.

\section{Outcomes and measures}

We stratified outcomes by type of surgery (gynecologic or nongynecologic), but we did not compare the 2 groups statistically except for medicolegal outcomes; rather, we stratified outcomes to provide context for the peer expert opinion in the medicolegal cases.

\section{Statistical analysis}

We used SAS software, version 9.4 (SAS Institute) for all statistical analyses of legal cases. These analyses summarized patient characteristics, types and mechanisms of injury, clinical management of injury and contributing factors ${ }^{20}$ at an aggregate level using descriptive statistics. We compared medicolegal outcomes between the gynecologic and nongynecologic groups, applying the $\chi^{2}$ or Fisher exact test for categoric variables. We used the step-down Bonferroni option of the MULTTEST procedure in SAS to adjust for multiple comparisons, using raw $p$ values as data points. The number of comparisons was not determined a priori. All tests were 2-tailed, and, for all analyses, we considered $p$ values $<0.05$ to be statistically significant.

In a secondary analysis, we examined complaints to a regulatory authority to gain deeper insight into nontechnical contributing factors. We characterized these factors using the CMPA's contributing factors framework ${ }^{20}$ and manually reviewed cases in depth to identify specific themes.

\section{Results}

Between 2013 and 2017, the CMPA closed 467 civil legal cases involving abdominopelvic procedures, of which 181 involved an intraoperative injury. An additional 88 complaints to regulatory authorities met the inclusion criteria. Among the 181 civil legal cases, gynecologic surgeons, general surgeons and urologists were involved in 177 cases $(97.8 \%)$, and other surgical specialists were involved in 4 cases $(2.2 \%)$. Involved surgeons had a median time since graduation from medical school of 22.3 (interquartile range 13.329.7) years.

Patient characteristics are reported in Table 1. Patients had a median age of 47 years, $33(18.2 \%)$ had a body mass index of 30 or greater, and the majority (78/111 nongynecologic patients [70.2\%] and 63/70 gynecologic patients [90.0\%]) were preoperatively considered healthy (ASA classification 1 or 2). The most common nongynecologic procedure was cholecystectomy (51 patients [45.9\%]), and the most common gynecologic procedure was hysterectomy (44 [62.9\%]). Most patients (155 [85.6\%]) had undergone an elective procedure.
Table 1. Characteristics of patients who experienced intraoperative injury from abdominopelvic surgery, Canadian Medical Protective Association civil legal cases, closed 2013-2017

\begin{tabular}{|c|c|c|c|}
\hline \multirow[b]{2}{*}{ Characteristic } & \multicolumn{3}{|c|}{ No. $(\%)$ of patients* } \\
\hline & $\begin{array}{c}\text { All cases } \\
n=181\end{array}$ & $\begin{array}{c}\text { Nongynecologic } \\
n=111\end{array}$ & $\begin{array}{c}\text { Gynecologic } \\
n=70\end{array}$ \\
\hline Age, median (IQR), yr & $47(39-61)$ & $54(38-66)$ & $44(40-50)$ \\
\hline Female sex & $127(70.2)$ & $57(51.4)$ & $70(100.0)$ \\
\hline Body mass inde $x \geq 30$ & $33(18.2)$ & $23(20.7)$ & $10(14.3)$ \\
\hline Previous abdominal or pelvic surgery & 59 (32.6) & $28(25.2)$ & $31(44.3)$ \\
\hline \multicolumn{4}{|l|}{ ASA classification } \\
\hline 1: normal healthy patient & $51(28.2)$ & $28(25.2)$ & 23 (32.9) \\
\hline 2: mild systemic disease & $90(49.7)$ & $50(45.0)$ & $40(57.1)$ \\
\hline $\begin{array}{l}\text { 3: severe systemic disease; } \\
\text { non-life-threatening }\end{array}$ & $33(18.2)$ & 27 (24.3) & $6(8.6)$ \\
\hline $\begin{array}{l}\text { 4: severe systemic disease; } \\
\text { constant threat to life }\end{array}$ & $1(0.6)$ & $1(0.9)$ & $0(0.0)$ \\
\hline Unknown & $6(2.2)$ & $5(2.7)$ & $1(1.4)$ \\
\hline \multicolumn{4}{|l|}{ Surgery acuity } \\
\hline Elective & $155(85.6)$ & $87(78.4)$ & $68(97.1)$ \\
\hline Urgent & $26(14.4)$ & $24(21.6)$ & $2(2.9)$ \\
\hline \multicolumn{4}{|l|}{ Type of surgery } \\
\hline Cholecystectomy & $51(28.2)$ & $51(45.9)$ & - \\
\hline Hysterectomy alone & 24 (13.3) & - & 24 (34.3) \\
\hline $\begin{array}{l}\text { Gastrointestinal tract (stomach, } \\
\text { bowel, rectum) }\end{array}$ & $23(12.7)$ & $23(20.7)$ & - \\
\hline $\begin{array}{l}\text { Hysterectomy with oophorectomy } \\
\text { and/or salpingectomy }\end{array}$ & $20(11.0)$ & - & $20(28.6)$ \\
\hline $\begin{array}{l}\text { Oophorectomy and/or } \\
\text { salpingectomy }\end{array}$ & $19(10.5)$ & - & $19(27.1)$ \\
\hline Hernia repair & $9(5.0)$ & $9(8.1)$ & - \\
\hline $\begin{array}{l}\text { Abdominal or pelvic cavity } \\
\text { (mesentery, lysis of adhesions, } \\
\text { diaphragm) }\end{array}$ & $8(4.4)$ & $5(4.5)$ & $3(4.3)$ \\
\hline Appendectomy & $7(3.9)$ & $7(6.3)$ & - \\
\hline Nephrectomy & $7(3.9)$ & $7(6.3)$ & - \\
\hline Pelvic floor repair & $4(2.2)$ & - & $4(5.7)$ \\
\hline Prostatectomy & $3(1.7)$ & $3(2.7)$ & - \\
\hline Pancreaticoduodenectomy & $3(1.7)$ & $3(2.7)$ & - \\
\hline Other urinary & $2(1.1)$ & $2(1.8)$ & - \\
\hline Liver lobectomy & $1(0.6)$ & $1(0.9)$ & - \\
\hline
\end{tabular}




\section{Frequency and types of injuries}

The frequencies and types of injuries in the legal cases are shown in Table 2. Legal cases most often involved injuries of the bowel, vasculature and/or ureter (115 cases [63.5\%]). Bile duct injuries (32 [17.7\%]) were specific to cholecystectomy. Nearly two-thirds of all injuries occurred during dissection or from inadvertent ligation of a structure, regardless of the type of approach (34/55 [61.8\%] with laparotomy, 83/126 [65.9\%] with laparoscopy). Entry-related injuries occurred in $23(18.2 \%)$ of the laparoscopic cases; 7 involved a Veress needle, and 16 involved a trocar injury.

Table 2. Frequencies and types of injury from abdominopelvic surgery

\begin{tabular}{|c|c|c|c|c|c|c|c|c|}
\hline \multirow[b]{2}{*}{ Characteristic } & \multicolumn{8}{|c|}{ Location or type of injury; no. of cases ( $\%$ of all cases)* } \\
\hline & $\begin{array}{c}\text { All cases } \\
n=181\end{array}$ & $\begin{array}{c}\text { Bowelt } \\
n=53\end{array}$ & $\begin{array}{c}\text { Bile duct } \\
n=32\end{array}$ & $\begin{array}{c}\text { Vascular } \\
n=32\end{array}$ & $\begin{array}{l}\text { Ureter } \\
n=30\end{array}$ & $\begin{array}{c}\text { Bladder } \\
n=19\end{array}$ & $\begin{array}{c}\text { Other } \neq \\
n=8\end{array}$ & $\begin{array}{c}\text { Retained } \\
\text { surgical item§ } \\
n=25\end{array}$ \\
\hline \multicolumn{9}{|l|}{ Type of surgery } \\
\hline Nongynecologic & $111(61.3)$ & 27 (14.9) & $32(17.7)$ & $28(15.5)$ & $8(4.4)$ & $3(1.7)$ & 7 (3.9) & $16(8.8)$ \\
\hline Gynecologic & $70(38.7)$ & $26(14.4)$ & $0(0.0)$ & $4(2.2)$ & $22(12.2)$ & $16(8.8)$ & $1(0.6)$ & $9(5.0)$ \\
\hline \multicolumn{9}{|l|}{ Surgical approach* } \\
\hline Laparoscopic & $126(69.6)$ & $41(22.7)$ & $32(17.7)$ & $23(12.7)$ & $15(8.3)$ & $12(6.6)$ & 6 (3.3) & $12(6.6)$ \\
\hline Laparotomy & $55(30.4)$ & $12(6.6)$ & $0(0.0)$ & $9(5.0)$ & $15(8.3)$ & $7(3.9)$ & $2(1.1)$ & $13(7.2)$ \\
\hline \multicolumn{9}{|l|}{ Mechanism of injury* } \\
\hline During dissection & $79(43.6) \uparrow$ & $31(17.1)$ & $6(3.3)$ & $15(8.3)$ & $23(12.7)$ & $11(6.1)$ & $3(1.7)$ & NA \\
\hline Ligation/clip placement & $38(21.0)$ & $3(1.7)$ & $25(13.8)$ & $8(4.4)$ & $4(2.2)$ & $3(1.7)$ & $2(1.1)$ & NA \\
\hline Entry-related (e.g., trocar) & $23(12.7)$ & $10(5.5)$ & $0(0.0)$ & $7(3.9)$ & $1(0.6)$ & $3(1.7)$ & $2(1.1)$ & NA \\
\hline Thermal/cautery & $9(5.0)$ & $4(2.2)$ & $1(0.6)$ & $1(0.6)$ & $2(1.1)$ & $0(0.0)$ & $1(0.6)$ & NA \\
\hline During closure & 32 (3.9) & $4(2.2)$ & $0(0.0)$ & $1(0.6)$ & $1(0.6)$ & $2(1.1)$ & $0(0.0)$ & NA \\
\hline Unknown & $10(5.5)$ & $5(2.8)$ & $1(0.6)$ & $1(0.6)$ & $2(1.1)$ & $1(0.6)$ & $1(0.6)$ & NA \\
\hline \multicolumn{9}{|c|}{$\begin{array}{l}\text { NA = not applicable. } \\
\text { *Some patients had more than } 1 \text { injury and mechanism (and approach). } \\
\text { tIncludes esophagus (2), stomach (2), small bowel (29), colon (15) and rectum (10). } \\
\text { fIncludes liver (4), uterus (1), spleen (1), kidney (1) and nerve (1). } \\
\text { §These most often included failures in surgical count procedures (e.g., surgical sponge, instruments) and also equipment breakdown (e.g., trocar ring, metallic edge of an endopouch, } \\
\text { surgical bag, tip of uterine manipulator, bulb syringe, strip of insulation from a monopolar laparoscopic instrument). } \\
\text { ๆIncluded in cases in which cautery was used with dissection. }\end{array}$} \\
\hline
\end{tabular}

Table 3. Clinical management and patient outcomes following injury from abdominopelvic surgery

\begin{tabular}{|c|c|c|c|}
\hline \multirow[b]{2}{*}{ Characteristic } & \multicolumn{3}{|c|}{ No. (\%) of cases } \\
\hline & $\begin{array}{l}\text { All cases } \\
n=181\end{array}$ & $\begin{array}{c}\text { Nongynecologic } \\
\quad n=111\end{array}$ & $\begin{array}{c}\text { Gynecologic } \\
n=70\end{array}$ \\
\hline \multicolumn{4}{|l|}{$\begin{array}{l}\text { Surgical phase of injury } \\
\text { discovery }\end{array}$} \\
\hline Intraoperative & $43(23.8)$ & $30(27.0)$ & $13(18.6)$ \\
\hline $\begin{array}{l}\text { Postoperative same } \\
\text { admission }\end{array}$ & $43(23.8)$ & $27(24.3)$ & $16(22.9)$ \\
\hline Postdischarge & $95(52.5)$ & $54(48.6)$ & $41(58.6)$ \\
\hline \multicolumn{4}{|l|}{ Management of injury* } \\
\hline Intraoperative repair & $19(10.5)$ & $10(9.0)$ & 9 (12.9) \\
\hline Return to operating room & $139(76.8)$ & $86(77.5)$ & $53(75.7)$ \\
\hline $\begin{array}{l}\text { Transfer to tertiary care } \\
\text { centre }\end{array}$ & $40(22.1)$ & 37 (33.3) & $3(4.3)$ \\
\hline $\begin{array}{l}\text { Transfer to intensive } \\
\text { care unit }\end{array}$ & 35 (19.3) & $27(24.3)$ & $8(11.4)$ \\
\hline Conservative treatment & $19(10.5)$ & $11(9.9)$ & $8(11.4)$ \\
\hline \multicolumn{4}{|l|}{ Patient harm } \\
\hline Death & $25(13.8)$ & $21(18.9)$ & $4(5.7)$ \\
\hline Severe & 55 (30.4) & $38(34.2)$ & $17(24.3)$ \\
\hline Moderate/mild & $101(55.8)$ & 52 (46.8) & $49(70.0)$ \\
\hline
\end{tabular}

\section{Clinical management and patient outcomes}

In three-quarters (138 [76.2\%]) of the legal cases, injuries were recognized postoperatively, often after the patient had been discharged from hospital (95 [52.5\%]) (Table 3). In $29(20$ [69.0\%] in the nongynecologic group and 9 [31.0\%] in the gynecologic group) of the 43 cases in which the surgeon recognized the injury intraoperatively, another surgical specialist such as a general surgeon urologist or vascular surgeon assisted with the repair.

In more than three-quarters of the legal cases (139 [76.8\%]), the patient was returned to the operating room for surgical repair. Nongynecologic patients often required transfer to a tertiary care centre (37 [33.3\%]) or intensive care (27 [24.3\%]), and often experienced severe harm (38 [34.2\%]) or died (21 [18.9\%]).

Severe harm and death were more commonly associated with cases in which the injury was recognized intraoperatively $(25 / 43$ [58.1\%]) or postoperatively during the same hospital stay (24/43 [55.8\%]) than after discharge (31/95 [32.6\%]). 


\section{Medicolegal outcomes}

Medicolegal outcomes based on peer expert opinion in the legal cases are shown in Table 4. Peer experts in nongynecologic cases were more likely than those in gynecologic cases to include criticisms of a provider in a harmful incident $(79[71.2 \%]$ v. $30[42.9 \%], p<0.01)$ and less likely to view injuries as inherent risks of surgery (16 [14.4\%] v. 31 [44.3\%], $p<0.01)$.

Of the 181 legal cases, 103 (56.9\%) ended in favour of the plaintiff. Cases that resolved in favour of the surgeon often involved injuries that peer experts deemed to be inherent risks of surgery $(64 / 78[82.0 \%])$, or the hospitals

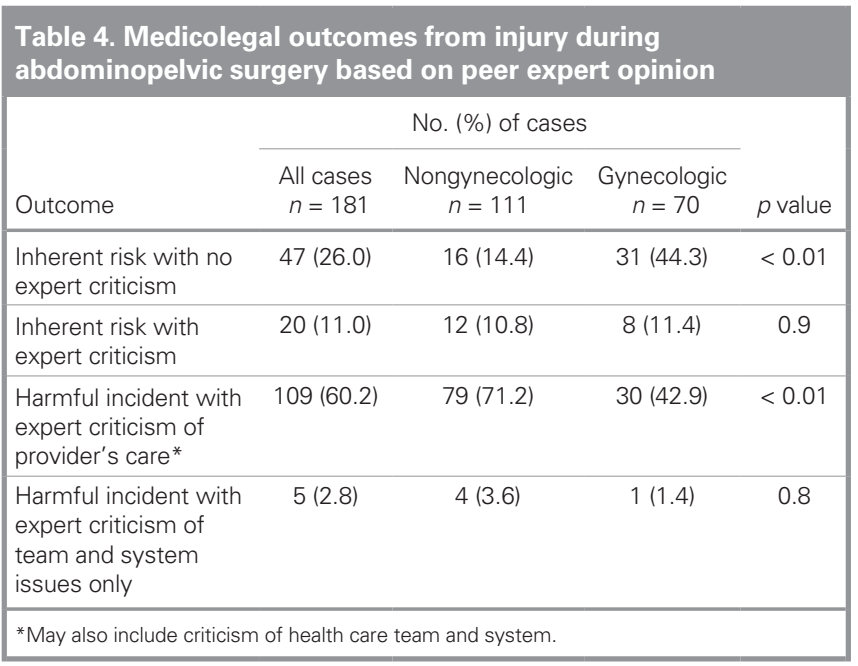

Table 5. Factors contributing to intraoperative injuries based on peer expert opinion in legal cases with criticism of care

\begin{tabular}{|c|c|c|c|}
\hline \multirow[b]{2}{*}{ Contributing factor } & \multicolumn{3}{|c|}{ No. $(\%)$ of cases* } \\
\hline & $\begin{array}{l}\text { All cases } \\
n=134\end{array}$ & $\begin{array}{c}\text { Nongynecologic } \\
n=95\end{array}$ & $\begin{array}{c}\text { Gynecologic } \\
n=39\end{array}$ \\
\hline Provider clinical care & $110(82.1)$ & $80(84.2)$ & $30(76.9)$ \\
\hline $\begin{array}{l}\text { Clinical evaluation and } \\
\text { decision-making }\end{array}$ & 58 (43.3) & $44(46.3)$ & 14 (35.9) \\
\hline $\begin{array}{l}\text { Deficient knowledge, skill } \\
\text { or technique }\end{array}$ & 53 (39.6) & $41(43.2)$ & $12(30.8)$ \\
\hline $\begin{array}{l}\text { Misidentification of } \\
\text { anatomy }\end{array}$ & 37 (27.6) & 34 (35.8) & $3(7.7)$ \\
\hline $\begin{array}{l}\text { Delayed recognition of } \\
\text { injury }\end{array}$ & 28 (20.9) & $21(22.1)$ & 7 (17.9) \\
\hline Procedural violation & $27(20.1)$ & $16(16.8)$ & $11(28.2)$ \\
\hline $\begin{array}{l}\text { Team communication } \\
\text { factors }\end{array}$ & $62(46.3)$ & $45(47.4)$ & $17(43.6)$ \\
\hline Informed consent & $40(29.9)$ & $28(29.5)$ & $12(30.8)$ \\
\hline Documentation & 33 (24.6) & $26(27.4)$ & 7 (17.9) \\
\hline System factors & $15(11.2)$ & $11(11.6)$ & $4(10.3)$ \\
\hline $\begin{array}{l}\text { Equipment or resource } \\
\text { issues }\end{array}$ & $9(6.7)$ & $7(7.4)$ & $2(5.1)$ \\
\hline Administrative protocols & $8(6.0)$ & $6(6.3)$ & $2(5.1)$ \\
\hline
\end{tabular}

were held solely responsible for the harmful incident $(6 / 78$ $[7.7 \%])$. Eight cases were either not pursued or were dismissed before trial.

\section{Contributing factors}

\section{Technical}

Peer experts in the legal cases identified contributing factors relevant to the medicolegal matter (see Appendix 1, Supplemental Table S4 for contributing factor terminology). Within the subgroup of 134 legal cases with peer expert criticism, the nature of criticism related in most cases to a surgeon's perioperative clinical care (110 cases [82.1\%]) (Table 5). The most common peer expert criticism was of a surgeon's clinical evaluation and decisionmaking (58 cases [43.3\%]), followed by deficient knowledge, skill or technique (53 [39.6\%]).

Deficient clinical evaluation and decision-making included the continued use of cautery without clear visualization, failure to confirm ureter patency at the end of surgery and failure to perform cholangiography intraoperatively. Of the 36 cholecystectomy cases with criticism of the surgeon's care, $15(41.7 \%)$ involved failure to obtain a critical view of the anatomy, leading to ligation or transection of the common bile duct. Recognizing anatomy was also a factor in cases of ureteric injuries, which occurred predominantly in gynecologic surgeries (22/30 [73.3\%]). Peer experts were frequently critical of the surgeon's technical skills when the operative note did not describe efforts to identify or protect important structures.

Peer experts were critical of delays in recognizing the injury in 28 cases $(20.9 \%)$ (Table 5), including 14 cases in which injuries were diagnosed after the patient had been discharged. However, peer experts were critical of the delay in only one-quarter $(16 / 63$ [25.4\%]) of cases in which the patient alleged a delay in diagnosis.

\section{Nontechnical}

Peer experts noted procedural violations such as nonadherence to a surgical safety protocol or improper use of equipment in 16/95 nongynecologic legal cases (16.8\%) and $11 / 39$ gynecologic legal cases (28.2\%). Most cases of retained surgical items involved failure by health care providers to adhere to surgical count processes. There were also cases in which pieces of equipment were retained owing to equipment breakdown or deficient hospital safety protocols (e.g., maintenance). In all of these cases, physicians did not identify the retained surgical item until after discharge, often not for several months. In 21/25 cases $(84.0 \%)$ involving a retained surgical item, the hospital contributed to the settlement or award.

A secondary analysis of the 88 complaints to regulatory authorities (49 nongynecologic and 39 gynecologic cases) showed that regulatory authorities in these cases urged surgeons to address deficient hospital or office protocols that 
contributed to inadequate management and follow-up of patient care. Regulatory authorities recognized that surgeons encountered equipment issues that affected their performance and that, although hospitals are responsible for providing surgical instruments, surgeons also have some responsibility for the equipment they use.

Regulatory authorities recognized breakdown in communication among health care providers, including failure to convey the urgency of a patient's clinical situation with other team members, inadequate handover, and failure to coordinate patient care or weekend coverage, as a factor contributing to patient injury. In cases in which breakdown in communication involved teams, regulatory authorities urged surgeons to take a leadership role to improve the existing hospital protocols.

Regulatory authority cases included recommendations for surgeons on improving discussions regarding consent with patients and family, which should include explanations of material risks and alternative treatment options. Peer experts in legal cases also noted their concerns regarding inadequate informed consent (Table 5). Regulatory authorities reminded surgeons of the need to hold disclosure meetings with patients and families (when appropriate) and to discuss intraoperative events. Furthermore, they reinforced the importance of using clear terminology and language appropriate to the patient's needs.

Other criticisms related to inadequate documentation. These deficiencies affected continuity of care, for example, when documentation was illegible or lacked detailed observations on the patient's assessment or care process. Regulatory authorities considered operative reports incomplete if they lacked details of the intraoperative events or ongoing management of care.

\section{Discussion}

Surgical safety should be a constant driver for advances in surgical training and practices, yet there are limited data on surgical incidents to inform these efforts. ${ }^{22} \mathrm{We}$ identified 181 civil legal cases and 88 complaints to regulatory authorities closed by the CMPA between 2013 and 2017 that involved injuries during abdominopelvic surgery. Many patients experienced severe harm or died. Surgeons named in these cases had been in practice for a median of 22.3 years, reflecting that surgeons new to practice were not at highest risk for complaints related to these types of injuries. Among the civil legal cases, injuries occurred most commonly during cholecystectomy and hysterectomy, likely reflecting the prevalence of these operations in Canada. ${ }^{23}$ The most common injuries involved the bowel, vasculature, bile duct and ureters, as found previously. ${ }^{15,16}$ The types of injuries identified align with those in previous studies of intraoperative injury in abdominopelvic surgery, which similarly involved predominantly healthy patients who had undergone elective surgery. ${ }^{15,24}$
This serves as a reminder that severe injuries can occur during procedures otherwise expected to be low risk.

Laparoscopy was the most common approach in our study. It is noteworthy that the frequency of injuries related to laparoscopic entry ( $18.2 \%$ of laparoscopic cases) was substantially lower than in older reports. ${ }^{11,13}$ However, this frequency aligns with recent reports in which an estimated one-fifth of laparoscopic-related medicolegal cases involved entry-related injuries. ${ }^{24}$ Our data confirm that, regardless of approach, injuries most often occur during dissection, inadvertent ligation or transection of a structure. ${ }^{10,16}$ Collectively, these findings may suggest an evolution in the risks associated with minimally invasive approaches: as we gradually increase the frequency and complexity of laparoscopic surgery, the risks of entry may be declining, while the risks of dissection and ligation become more prevalent.

Although we expected that delays in recognizing injuries would be a criticism of surgical care, this was rarely the case in our study (20.9\% of cases with criticism of care). This finding may reflect the fact that the majority of severe injuries $(30 / 55$ [54.5\%]) were identified before discharge from hospital. We had hypothesized that gynecologic surgeons would be more likely to request the assistance of another surgeon in managing injuries, but this was not evident among our cases: in the majority of legal cases, other specialists were involved in surgical repair regardless of whether the initial surgery was gynecologic or nongynecologic.

Peer experts were critical of surgeons when the possibility of a surgical complication was not considered despite a worsening postoperative course.

A variety of factors may have contributed to medicolegal outcomes that were, on average, substantially better for gynecologic surgeons than for nongynecologic surgeons. Peer experts retained in the gynecologic surgery legal cases were more likely to view injuries as inherent risks of the procedure and were generally less critical of care. Possible explanations may relate to differing patient presentations and disease pathophysiology as well as medicolegal selection bias.

Differences may also relate to surgeons not describing attention to anatomy in the operative note. Ureteric injuries were noted more frequently in gynecologic cases and were most often recognized as an inherent risk of surgery. Documented attention to ureters in the operative note may have contributed to peer support. Nongynecologic surgery cases more often included criticism for misidentifying anatomy, including the bile duct. Peer experts in these cases scrutinized the operative note for evidence of the care taken to identify and protect critical structures. Overall, these findings may motivate surgical training programs to enhance both technical skills and documentation.

A key component of a successful medicolegal defence is a well-documented medical record, including the consent process. ${ }^{15,25}$ The challenges with obtaining informed consent 
for abdominopelvic surgery have been described. ${ }^{26,27}$ Interestingly, in our study, peer expert criticisms of the consent process were similar for gynecologic and nongynecologic procedures, regardless of the fact that there were better medicolegal outcomes for gynecologic patients. We did find, however, that nongynecologic cases had a higher proportion of peer expert criticisms relating to documentation.

\section{Limitations}

Medicolegal data are influenced by recall bias, and analyses are subject to hindsight, recognition and outcome biases. $^{28,29}$ The retrospective nature of factors contributing to the medicolegal cases imparted suggestions of association but not epidemiologic causation. Because, until recently, our coding framework captured a limited number of system issues, system-related factors may be underrepresented in our study. Furthermore, the data that we analyzed consisted of cases involving and reported by member physicians; these data should not be considered reflective of overall incidence. Many factors influence a person's decision to pursue a legal case or file a complaint with a regulatory authority, and these may vary greatly by context. Based on Canadian health administrative data for hospital and day surgery clinics ${ }^{6}$ and risk estimates in the literature ${ }^{4}$ more than 80000 patient safety incidents may have occurred in hospital and day surgery clinics in Ontario alone (Canada's most populous province) between 2012 and 2016.

\section{Conclusion}

Analyzing medicolegal data relating to surgical harm and the contributing factors involved strengthens a culture of learning and patient safety. Our findings support the need for continued quality improvement in routine surgical procedures to prevent intraoperative injuries. For surgeons and health care teams, our findings confirm the importance of appropriate clinical evaluation, communication and documentation. For administrators, there may be a need for more effective implementation of evidence-based surgical safety protocols to support clinicians in providing safe surgical care.

Affiliations: From Practice Improvement, Canadian Medical Protective Association, Ottawa, Ont. (Lefebvre, Mimeault); Medical Care Analytics, Canadian Medical Protective Association, Ottawa, Ont. (Devenny, Héroux, Bowman, Neilson, Calder); the Department of Obstetrics and Gynecology, University of Ottawa, Shirley E. Greenberg Women's Health Centre, Ottawa, Ont. (Singh); and the Clinical Epidemiology Program, Ottawa Hospital Research Institute, Ottawa, Ont. (Calder).

Competing interests: Kirsten Devenny, Diane Héroux, Cara Bowman, Heather Neilson, Richard Mimeault and Lisa Calder are employees of the Canadian Medical Protective Association. Sukhbir Singh reports grants and personal fees from AbbVie, Bayer and Allergan, outside the submitted work. No other competing interests were declared.

Contributors: C. Bowman, G. Lefebvre, D. Héroux, K. Devenny, S. Singh and L.A. Calder designed the study. C. Bowman acquired the data, which all authors analyzed. C. Bowman, G. Lefebvre, K. Devenny and H. Neilson wrote the manuscript, which C. Bowman, G. Lefebvre, D. Héroux, K. Devenny, R. Mimeault, S. Singh and L.A. Calder critically revised. All authors gave final approval of the article to be published.

Content licence: This is an Open Access article distributed in accordance with the terms of the Creative Commons Attribution (CC BYNC-ND 4.0) licence, which permits use, distribution and reproduction in any medium, provided that the original publication is properly cited, the use is noncommercial (i.e., research or educational use), and no modifications or adaptations are made. See: https://creativecommons. org/licenses/by-nc-nd/4.0/.

\section{References}

1. Brennan TA, Leape LL, Laird NM, et al. Incidence of adverse events and negligence in hospitalized patients. N Engl 7 Med 1991;324:370-6.

2. Leape LL, Brennan TA, Laird NM, et al. The nature of adverse events in hospitalized patients - results of the Harvard Medical Practice Study II. N Engl 7 Med 1991;324:377-84.

3. Thomas EJ, Studdert DM, Burstin HR, et al. Incidence and types of adverse events and negligent care in Utah and Colorado. Med Care 2000;38:261-71.

4. Baker GR, Norton PG, Flintoft V, et al. The Canadian Adverse Events Study: the incidence of adverse events among hospital patients in Canada. CMA7 2004;170:1678-86.

5. Makary MA, Daniel M. Medical error - the third leading cause of death in the US. BMF 2016;353:i2139.

6. Measuring patient harm in Canadian hospitals: technical report. Ottawa: Canadian Institute for Health Information; 2016.

7. ACS National Surgical Quality Improvement Program. Chicago: American College of Surgeons. Available: https://www.facs.org/ quality-programs/acs-nsqip (accessed 2019 Jan. 10).

8. WHO surgical safety checklist. Geneva: World Health Organization; 2009. Available: http://whqlibdoc.who.int/publications/2009/ 9789241598590_eng_Checklist.pdf?ua=1 (accessed 2019 Jan. 8).

9. Satitniramai S, Manonai J. Urologic injuries during gynecologic surgery, a 10-year review. 7 Obstet Gynaecol Res 2017;43:557-63.

10. Walden PA, Zeybek B, Phelps JY. Understanding the legal essentials of a bowel injury lawsuit in minimally invasive gynecologic surgery. $\mathcal{F}$ Minim Invasive Gynecol 2018;25:30-7.

11. Llarena NC, Shah AB, Milad MP. Bowel injury in gynecologic laparoscopy: a systematic review. Obstet Gynecol 2015;125:1407-17.

12. Vilos GA, Ternamian A, Vilos AG, et al. Direct laparoscopic trocar insertion: lessons learned from nine litigated cases. 7 Minim Invasive Gynecol 2017;24:960-70.

13. Vilos GA. Litigation of laparoscopic major vessel injuries in Canada. 7 Am Assoc Gynecol Laparosc 2000;7:503-9.

14. Gilmour DT, Baskett TF. Disability and litigation from urinary tract injuries at benign gynecologic surgery in Canada. Obstet Gynecol 2005;105:109-14.

15. Sandberg EM, Bordewijk EM, Klemann D, et al. Medical malpractice claims in laparoscopic gynecologic surgery: a Dutch overview of 20 years. Surg Endosc 2017;31:5418-26.

16. Scurr JR, Brigstocke JR, Shields DA, et al. Medicolegal claims following laparoscopic cholecystectomy in the UK and Ireland. Ann $R$ Coll Surg Engl 2010;92:286-91.

17. Kravitz RL, Rolph JE, McGuigan K. Malpractice claims data as a quality improvement tool - I. Epidemiology of error in four specialties. FAMA 1991;266:2087-92. 
18. International Statistical Classification of Diseases and Related Health Problems, 10th revision. Geneva: World Health Organization; 2015.

19. Canadian Classification of Health Interventions. Ottawa: Canadian Institute for Health Information; 2015.

20. McCleery A, Devenny K, Ogilby C, et al. Using medicolegal data to support safe medical care: a contributing factor coding framework. $\mathcal{F}$ Healthc Risk Manag 2018;38:11-8.

21. Hoppes M, Mitchell J. Serious safety events: a focus on harm classification: deviation in care as link [edition 2 of Getting to Zero White Paper series]. Chicago: American Society for Healthcare Risk Management; 2014.

22. Noble DJ, Pronovost PJ. Underreporting of patient safety incidents reduces health care's ability to quantify and accurately measure harm reduction. 7 Patient Saf 2010;6:247-50.

23. Inpatient hospitalizations, surgeries and newborn indicators, 20162017. Ottawa: Canadian Institute for Health Information; 2018. Avail- able: https://www.cihi.ca/sites/default/files/document/hospchild -inpatientalosdiagsurg-2016-2017-en.xlsx (accessed 2018 Apr. 19).

24. Wind J, Cremers JE, van Berge Henegouwen MI, et al. Medical liability insurance claims on entry-related complications in laparoscopy. Surg Endosc 2007;21:2094-9.

25. Gutheil TG. Boundaries, blackmail, and double binds: a pattern observed in malpractice consultation. 7 Am Acad Psychiatry Law 2005; 33:476-81.

26. Chen AM, Leff DR, Simpson J, et al. Variations in consenting practice for laparoscopic cholecystectomy. Ann R Coll Surg Engl 2006;88: 482-5.

27. Shiwani MH, Gosling J. Variations in the quality of consent for open mesh repair of inguinal hernia. Hernia 2009;13:73-6.

28. Annunziata A. Retrospective bias in expert evidence: effects on patient and doctor safety. Emerg Med Australas 2009;21:80-3.

29. Hugh TB, Tracy GD. Hindsight bias in medicolegal expert reports. Med F Aust 2002;176:277-8. 